\title{
Improvement in sinterability and high-temperature mechanical properties by grain boundary design for high purity mullite ceramics: Crystallization of grain-boundary glassy phase
}

\author{
Takeshi KUMAZAWA ${ }^{1,2, \dagger}$ and Hisao SUZUKI ${ }^{2,3}$ \\ ${ }^{1}$ Technical Research Laboratory, Mino Ceramic Co., Ltd., 1-46 Kamezaki Kitaura-cho, Handa, Aichi 475-0027, Japan \\ ${ }^{2}$ Graduate School of Science and Technology, Shizuoka University, 3-5-1 Johoku, Naka-ku, Hamamatsu 432-8561, Japan \\ ${ }^{3}$ Shizuoka University, Research Institute of Electronics, 3-5-1 Johoku, Naka-ku, Hamamatsu 432-8561, Japan
}

\begin{abstract}
High-purity mullite ceramics are fabricated to improve their high-temperature mechanical properties using an intelligent eco-friendly sintering process with a transient silica-rich liquid phase formed during sintering, followed by the crystallization of the residual glassy phase of $\mathrm{SiO}_{2}$. The fabricated ceramics possess high density and excellent high-temperature flexural strength. The sinterability of the mullite ceramics improved dramatically when silica-rich compositions were used. This can be attributed to the viscous flow of the silica-rich viscous liquid phase formed during sintering at high temperatures. To increase the high-temperature flexural strength without degrading the fracture toughness, the residual boundary phase was crystallized into cristobalite by controlling its amount and size. The crystallite size of the precipitated cristobalite obtained using suitable postannealing conditions, i.e., at $1500^{\circ} \mathrm{C}$ for $120 \mathrm{~h}$ or more, was suppressed; very fine crystals of size 33-38 nm were obtained. The flexural strength measured at $1400{ }^{\circ} \mathrm{C}$ for the specimens, which were post-annealed at $1500{ }^{\circ} \mathrm{C}$ for $120 \mathrm{~h}$, exceeded that of the as-sintered specimen without resulting in any degradation in fracture toughness at room temperature. These results suggest that suitable grain boundary design conditions, including the composition and post-annealing conditions, can improve the sinterability and high-temperature mechanical properties of the highly pure mullite ceramics at low sintering temperatures. Such grain boundary design can lead to the development of eco-friendly processing of low-temperature sintering for high-performance structural ceramics.
\end{abstract}

(C)2020 The Ceramic Society of Japan. All rights reserved.

Key-words : Mullite, Cristobalite, Sinterability, High-temperature flexural strength, Transient liquid phase sintering, Post-annealing

[Received April 24, 2020; Accepted July 6, 2020]

\section{Introduction}

Mullite ceramics obtained from high-purity raw materials have been reported in several studies from the viewpoint of their high-temperature mechanical properties. ${ }^{1)-7)}$ In these studies, it was clear that mullite ceramics with ideally controlled microstructures exhibit a hightemperature strength, better creep resistance, low thermal expansion, and low thermal conductivity than non-oxide ceramics, such as silicon nitride and silicon carbide ceramics. ${ }^{1), 8)-10)}$ Therefore, mullite ceramics have attracted significant attention as potential engineering ceramics for high-temperature applications in air. ${ }^{11), 12)}$

We investigated the high-temperature mechanical properties of mullite ceramics fabricated from raw powders

Corresponding author: T. Kumazawa; E-mail: kumazawa@ mino-ceramic.co.jp

\$ Preface for this article: Dol http://doi.org/10.2109/jcersj2. 128.P10-1 with a stoichiometric composition of $3 \mathrm{Al}_{2} \mathrm{O}_{3} \cdot 2 \mathrm{SiO}_{2}$ (hereafter abbreviated as 3:2 mullite, meaning $60 \mathrm{~mol} \% \mathrm{Al}_{2} \mathrm{O}_{3}$ composition). ${ }^{4}$ These mullite ceramics exhibited superior flexural strength up to $1400^{\circ} \mathrm{C}$. In addition, the mullite ceramics with compositions near stoichiometry exhibited totally different sintering behavior because of the difference in the amount of liquid phase formed during hightemperature sintering, depending on the homogeneity and the size of the raw powders. ${ }^{13), 14)}$ Consequently, sinterability of mullite ceramics with silica-rich compositions is good even at lower temperatures, whereas that of 3:2 mullite and mullite ceramics with alumina-rich compositions is poor. Moreover, the silica to alumina ratio and their homogeneity had a large effect on the mechanical properties of the resulting mullite ceramics at high temperatures. ${ }^{6)}$ Mullite ceramics having silica-rich compositions usually densified at lower temperatures as compared with 3:2 mullite. Their flexural strength increased at around $1300^{\circ} \mathrm{C}$, then dramatically decreased above $1400^{\circ} \mathrm{C}$ due to the stress relaxation caused by the softening of the 
glassy phase at the boundary. In contrast, the mullite ceramics having alumina-rich compositions showed poor sinterability as compared with 3:2 mullite, and their flexural strength gradually decreased from room temperature to $1400^{\circ} \mathrm{C}$.

Densification of poorly sinterable material has been investigated in typical non-oxide engineering ceramics, such as silicon nitride and silicon carbide. ${ }^{15), 16)}$ Dense nonoxide ceramics have been successfully obtained by generating a liquid phase during sintering. Using fine $\alpha$-silicon nitride powder and high-purity $\mathrm{Y}_{2} \mathrm{O}_{3}(99.99 \mathrm{wt} \%)$ additive, Tsuge et al. obtained high-density silicon nitride ceramics with good high-temperature flexural strength using hot pressing. ${ }^{17)}$ However, the oxidation of silicon nitride ceramics under air atmosphere accelerated at temperatures above $1200^{\circ} \mathrm{C}$. Therefore, it is difficult to use silicon nitride ceramics at high temperatures for a long time. For silica and alumina systems, silica-rich powders are more sinterable than single-phase mullite powder because of the liquid phase formed during sintering. ${ }^{13)}$ If the sintering temperature is decreased below $1600^{\circ} \mathrm{C}$, then the production cost is reduced because a special furnace with an expensive heating element is no longer required; this is in line with the Sustainable Development Goals. Therefore, the sintering of mullite ceramics with silica-rich compositions is a promising method for developing hightemperature structural ceramics through eco-friendly processing. However, in such systems the residual glassy phase usually degrades the mechanical properties of mullite ceramics at room temperature and at higher temperatures by decreasing the viscosity of the boundary phase. ${ }^{6}$

The crystallization of the glassy phase in the grain boundary by reheating after sintering (i.e., post-annealing) is one of the typical methods used to suppress the decrease in the flexural strength of silicon nitride ceramics at high temperatures. ${ }^{18)}$ A successful example of this is the suppression of reduction in the bending strength in $\mathrm{N}_{2}$ atmosphere up to $1500{ }^{\circ} \mathrm{C}$ by crystallizing the grain boundaries of the residual glassy phase in a sintered silicon carbide ceramics. ${ }^{19), 20)}$ Additionally, silicon carbide ceramics sintered with a small amount of $\mathrm{Y}_{2} \mathrm{O}_{3}$ additive using hot pressing with a reduced amount of the liquid phase during sintering exhibited a very high bending strength of $1 \mathrm{GPa}$ at $2000^{\circ} \mathrm{C} .{ }^{21)}$ However, it is very difficult to develop hightemperature structural oxide ceramics usable in air, even by post-annealing.

Therefore, herein we focused on the sintering behavior of mullite ceramics with silica-rich compositions to obtain dense mullite ceramics at lower temperatures by means of an eco-friendly, transient liquid-phase sintering process. In addition, we tried to crystallize the grain boundary glassy phase in the resulting mullite ceramics to design the microstructure of the post-annealed mullite ceramics to have improved high-temperature mechanical properties. The effect of the precipitated cristobalite phase, which has $\alpha \leftrightarrows$ $\beta$ phase transition ${ }^{22)}$ with volume change and higher coefficient of thermal expansion than mullite, on the mechanical properties of the mullite ceramics was investigated.

\section{Experimental procedure}

Mullite precursor powders (Hokko Chemical, Tokyo, Japan), with alumina content of $60,64,68$, and $71.8 \mathrm{wt} \%$, were used as the starting raw material. These powders were calcined at $1450{ }^{\circ} \mathrm{C}$ for $1 \mathrm{~h}$ to crystallize amorphous powder into mullite. The aggregated rough powders were milled in methanol in an attrition mill (Model S-01S, Nippon Coke \& Engineering, Japan), which consisted of a nylon resin-lined pot and silicon nitride beads of $4 \mathrm{~mm}$ diameter. The obtained fine powders were isostatically pressed at $200 \mathrm{MPa}$ after uniaxial pressing using a metal mold. The compacted bodies were sintered from 1450 to $1690^{\circ} \mathrm{C}$ for $4 \mathrm{~h}$, at a heating rate of $10^{\circ} \mathrm{C} \cdot \mathrm{min}^{-1}$ in an electric furnace.

The sintered bodies $\left(\sim 40 \times 30 \times 5 \mathrm{~mm}^{3}\right)$ were cut into a rectangular shape, and the surfaces ground using a \#600 diamond wheel and chamfered. Then, specimens with dimensions of $3 \times 4 \times 38 \mathrm{~mm}^{3}$ were prepared for the standard JIS R1601 flexural strength test. These test specimens were placed in a platinum container for post-annealing, which was performed by annealing at $1500^{\circ} \mathrm{C}$ for 48,72 , $96,120,240$, and $360 \mathrm{~h}$ at a heating rate of $5^{\circ} \mathrm{C} \cdot \mathrm{min}^{-1}$ in air. The post-annealed specimens were cooled in the furnace.

The specific surface area of the starting raw materials was measured by the Brunauer-Emmett-Teller method using nitrogen as an absorption gas (Model Soapmatic 1800, Carlo Erba, Italy). The bulk densities of the sintered materials were estimated by Archimedes' method using distilled water as a displacement liquid based on the JISR1634 standard (Test methods for density and apparent porosity of fine ceramics). The relative density of specimens with different compositions was calculated from the measured bulk density and theoretical density. The theoretical density of mullite ceramics with different alumina contents used in this study were calculated using the rule of mixtures (mullite and silica) reported by Sato et al. ${ }^{23 \text { ) }}$ The phase identification of the raw materials and sintered bodies was conducted using X-ray diffraction (XRD, RAD-2B, Rigaku, Japan). Alumina and silica contents of the raw powders were measured using X-ray fluorescence (Model 3070, Rigaku, Japan). The crystallite size of cristobalite in the $60 \mathrm{wt} \%$ alumina content specimen annealed at $1500^{\circ} \mathrm{C}$ for various soaking durations was calculated using Scherrer's equation ${ }^{24)}$ from XRD patterns.

The microstructures were observed using a scanning electron microscope (SEM T300, JEOL, Japan). The specimens were prepared by thermal etching of the mirrorpolished surface at $1500{ }^{\circ} \mathrm{C}$ for $20 \mathrm{~min}$ or by chemical etching in a $1 \% \mathrm{HF}$ solution at $0^{\circ} \mathrm{C}$ for $24 \mathrm{~h}$. Furthermore, after the sintered body was thinned by ion milling, the microstructure of the sintered body was observed using a transmission electron microscope (TEM, JEM-4000FX, JEOL, Japan).

The thermal expansion coefficients of the sintered bodies were measured from room temperature to $1000^{\circ} \mathrm{C}$ in air using thermal mechanical analysis equipment (Model 
TMA-HT, Rigaku, Japan). Flexural strength in air was measured using a three-point bending test at a displacement rate (crosshead speed) of $0.5 \mathrm{~mm} \cdot \mathrm{min}^{-1}$ on a universal testing machine (DCS-2000, Shimadzu, Japan) using more than three specimens. Fracture toughness was measured at room temperature using the chevron-notched beam method and calculated by the equation given by Munz et al. ${ }^{25}$ )

\section{Results and discussion}

\subsection{Influence of sintering and post-annealing on microstructure and crystal phase}

Table 1 lists the alumina content analyzed by X-ray fluorescence, specific surface area, and the average diameter calculated from the specific surface area of the raw powders used herein. The specimen names in Table 1 depict the alumina content, e.g., $60 \mathrm{~A}$ means the specimen with $60 \mathrm{wt} \%$ alumina content. The particle size of every raw powder used was $\sim 100 \mathrm{~nm}$, irrespective of their type, indicating that they were very fine. However, the average diameter of the raw powders gradually decreased with an increase in alumina content, indicating that grain growth was enhanced with an increase in silica content in the raw powders during calcination by the viscous sintering, even at the relatively low temperature of $1450^{\circ} \mathrm{C}$.

The effect of the composition on the bulk density of the specimens sintered at temperatures from 1450 to $1690^{\circ} \mathrm{C}$ for $4 \mathrm{~h}$ is shown in Fig. 1. The temperatures, at which the bulk density leveled off, decreased dramatically with increasing amounts of silica content. For example, from this figure, $60 \mathrm{~A}$ and $64 \mathrm{~A}$ were seen to be fully densified at $\sim 1550$ and $1600{ }^{\circ} \mathrm{C}$, respectively. Meanwhile, the temperature at which full density was obtained for $71.8 \mathrm{~A}$ was $1650{ }^{\circ} \mathrm{C}$. The highest relative densities of the specimens were almost $100 \%$ at $1550{ }^{\circ} \mathrm{C}$ for $60 \mathrm{~A}$ and $1600^{\circ} \mathrm{C}$ for

Table 1. Chemical composition and specific surface area of the milled starting powders

\begin{tabular}{rccc}
\hline Symbol & $\begin{array}{c}\text { Alumina content } \\
\mathrm{wt} \%\end{array}$ & $\begin{array}{c}\text { Specific surface area } \\
\mathrm{m}^{2} \cdot \mathrm{g}^{-1}\end{array}$ & $\begin{array}{c}\text { Particle diameter } \\
\mathrm{nm}\end{array}$ \\
\hline 60A & 60.4 & 19.3 & 103.0 \\
$64 \mathrm{~A}$ & 63.8 & 20.6 & 95.2 \\
$68 \mathrm{~A}$ & 67.9 & 23.5 & 82.1 \\
$71.8 \mathrm{~A}$ & 71.7 & 24.6 & 77.4 \\
\hline
\end{tabular}

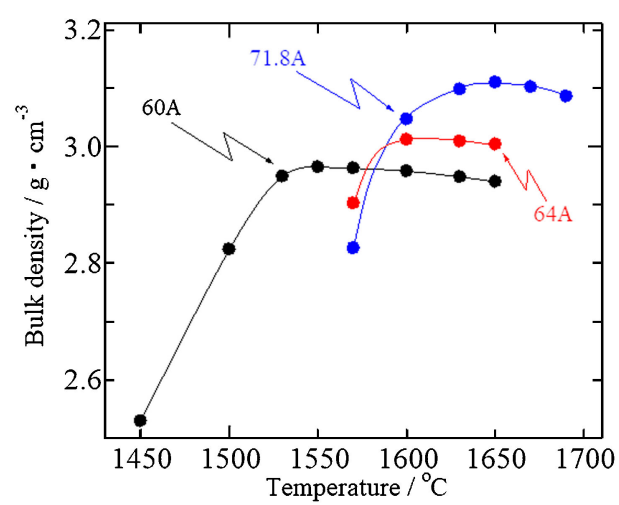

Fig. 1. Effect of sintering temperature for $4 \mathrm{~h}$ on the sinterability of the $\mathrm{SiO}_{2}-\mathrm{Al}_{2} \mathrm{O}_{3}$ compacts.
$64 \mathrm{~A}$, and $98.0 \%$ at $1650{ }^{\circ} \mathrm{C}$ for $71.8 \mathrm{~A}$. Thus, the sintering behavior in the silica-alumina system improved remarkably by increasing the silica content. This densification behavior in relation to composition was in accordance with the results described in our previous reports. ${ }^{13)}$

Figure 2 shows representative microstructures observed by SEM for $60 \mathrm{~A}, 64 \mathrm{~A}, 68 \mathrm{~A}$, and $71.8 \mathrm{~A}$ sintered at $1650{ }^{\circ} \mathrm{C}$ for $4 \mathrm{~h}$, chemically etched after polishing. It is seen that the size and numbers of the sharply etched grain boundaries, i.e., the chemically etched glassy grain boundaries, dramatically increased with increasing silica content in the specimen. In addition, mullite grains became elongated in the specimens with silica-rich compositions.

XRD patterns for the $60 \mathrm{~A}$ sintered at $1650^{\circ} \mathrm{C}$ and postannealed at $1500^{\circ} \mathrm{C}$ for different time periods from 0 to $240 \mathrm{~h}$ are shown in Fig. 3. A broad peak around $2 \theta=20^{\circ}$ in the as-sintered specimen, attributed to the amorphous phase, disappeared, and cristobalite was identified in all the specimens annealed for more than $48 \mathrm{~h}$. The diffraction intensity of the cristobalite increased with increasing annealing time up to $120 \mathrm{~h}$ and then leveled off, suggesting that the boundary glassy phase was almost crystallized by

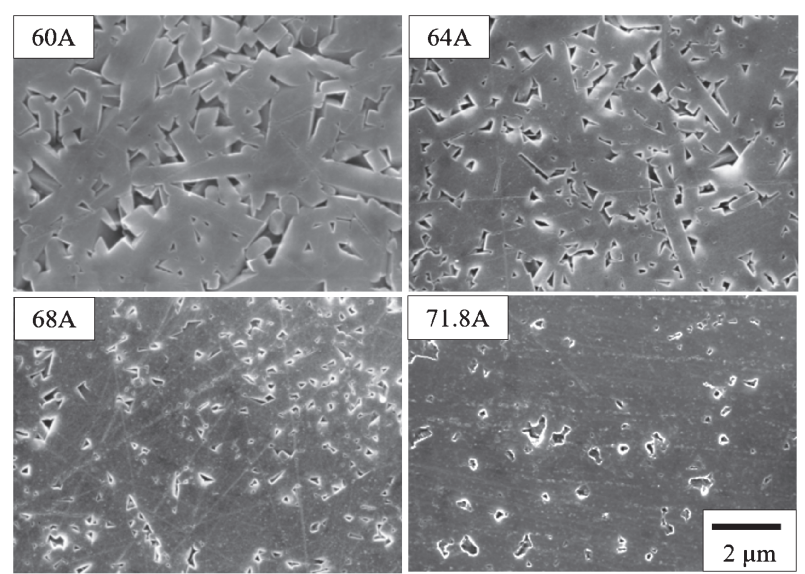

Fig. 2. Scanning electron micrographs of polished chemically etched surfaces [HF $1 \%$ (aq.) at $0{ }^{\circ} \mathrm{C}$ for $24 \mathrm{~h}$ ] of the specimens sintered at $1650^{\circ} \mathrm{C}$ for $4 \mathrm{~h}$.

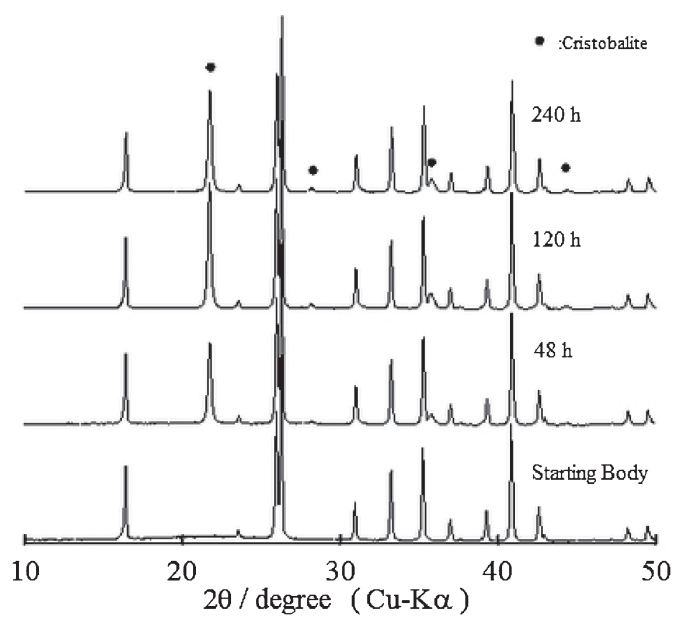

Fig. 3. XRD patterns of the $60 \mathrm{~A}$ specimen (sintered at $1650^{\circ} \mathrm{C}$ for $4 \mathrm{~h}$ ) post-annealed at $1500^{\circ} \mathrm{C}$ up to $240 \mathrm{~h}$. 


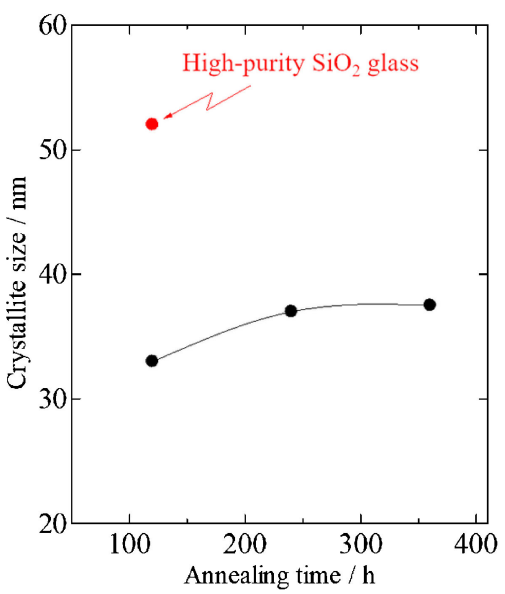

Fig. 4. Crystallite size of the $60 \mathrm{~A}$ specimen (sintered at $1650{ }^{\circ} \mathrm{C}$ for $4 \mathrm{~h}$ ) post-annealed at $1500^{\circ} \mathrm{C}$ for 120,240 , and $360 \mathrm{~h}$, respectively.

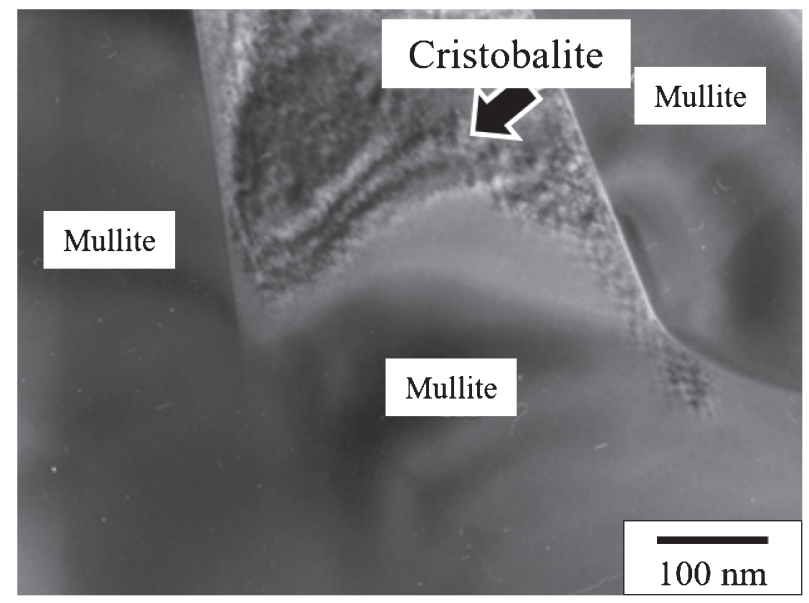

Fig. 5. Transmission electron micrograph of the grain boundary of the $60 \mathrm{~A}$ specimen (sintered at $1650^{\circ} \mathrm{C}$ for $4 \mathrm{~h}$ ) post-annealed at $1500^{\circ} \mathrm{C}$ for $120 \mathrm{~h}$.

post-annealing for $120 \mathrm{~h}$ or more. In addition, the peak position and the diffraction intensity of the mullite was almost the same for all the specimens. A detailed analysis of XRD patterns for $64 \mathrm{~A}, 68 \mathrm{~A}$, and $71.8 \mathrm{~A}$ annealed at $1500^{\circ} \mathrm{C}$ for $120 \mathrm{~h}$ revealed that the peak intensity of cristobalite decreased with decreasing silica content. Further, cristobalite was not identified in $71.8 \mathrm{~A}$ in spite of the presence of a small amount of glassy phase between the mullite boundaries.

Figure 4 shows the crystallite size of cristobalite precipitated in specimen $60 \mathrm{~A}$ post-annealed at $1500^{\circ} \mathrm{C}$ for 120 $360 \mathrm{~h}$, along with that of a high-purity commercial silica glass $(99.99 \mathrm{wt} \%)$ annealed at $1500^{\circ} \mathrm{C}$ for $120 \mathrm{~h}$. The crystallite size of cristobalite was $\sim 35 \mathrm{~nm}$, regardless of the annealing time, whereas that of the high-purity commercial silica glass was $\sim 52 \mathrm{~nm}$. The cristobalite precipitated by the post-annealing was found to have fine nanosized particles. Figure 5 shows the transmission electron micrograph of the grain boundary of the $60 \mathrm{~A}$ specimen post-annealed at $1500^{\circ} \mathrm{C}$ for $120 \mathrm{~h}$. The results of the XRD pattern for $60 \mathrm{~A}$ in Fig. 3 suggest that the glassy phase

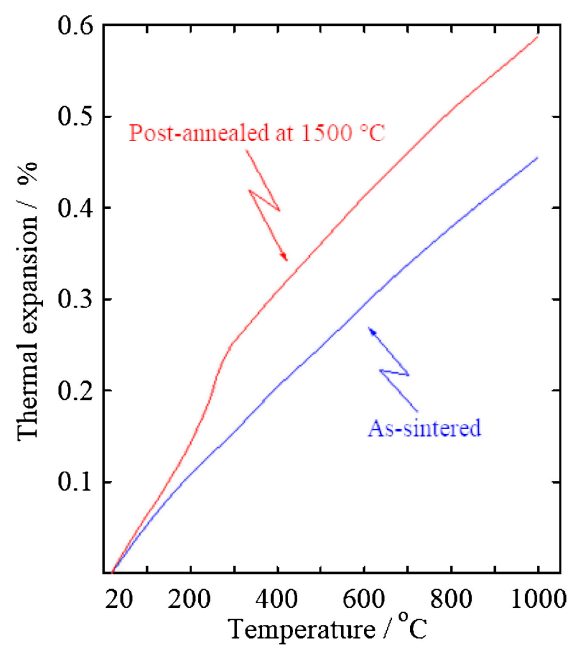

Fig. 6. Temperature-dependence of the thermal expansion of specimen $60 \mathrm{~A}$ (sintered at $1650^{\circ} \mathrm{C}$ for $4 \mathrm{~h}$ ): post-annealed at $1500^{\circ} \mathrm{C}$ for $120 \mathrm{~h}$, and as-sintered, respectively.

almost crystallized to cristobalite by post-annealing for more than $120 \mathrm{~h}$. Raj et al. studied the crystallization of the amorphous phase existing in a small area in several aluminum crystals using thermodynamic analysis. ${ }^{26)}$ They reported that crystallization of the amorphous phase existing at the grain boundaries depends on the angle between grain surfaces, and some parts resisted crystallization. Furthermore, a study on the crystallization behavior of the grain boundary glassy phase by $\mathrm{Clark}^{27)}$ revealed the presence of the residual glassy phase. Therefore, the TEM observation in the present study and the results in previous reports ${ }^{23), 26), 27)}$ imply that the grain boundary phase could consist of two phases, namely nanosized cristobalite and glassy phase. Here, the crystallite size of the cristobalite precipitated in the resulting mullite ceramics was larger than that observed by TEM but smaller than that precipitated by annealing pure quartz glass. It is expected that the crystallite size seen in the XRD pattern would be different from that directly observed in TEM because the cristobalite precipitated in the mullite was under tensile stresses from precise measurements of lattice constants. ${ }^{22)}$

\subsection{Effect of thermal mismatch on the me- chanical properties at room temperature}

Figure 6 shows the thermal expansion behavior from room temperature to $1000^{\circ} \mathrm{C}$ for specimen $60 \mathrm{~A}$ before and after post-annealing at $1500^{\circ} \mathrm{C}$ for $120 \mathrm{~h}$. A slope change at $\sim 250^{\circ} \mathrm{C}$ was observed in the thermal expansion curve for the post-annealed 60A. This slope change is ascribed to the transformation of cristobalite from $\alpha$ to $\beta$-phase, resulting in residual compressive stress in the sintered ceramics at higher temperatures. ${ }^{28)}$ In such a case, we can expect an improvement in the mechanical properties of the resulting ceramics at room temperature. ${ }^{29), 30)}$

Moreover, the fracture toughness of ceramics containing a second phase is affected by the residual stress caused by the difference between the coefficients of thermal expansion of the matrix and second phase. ${ }^{31)}$ The silica-alumina 


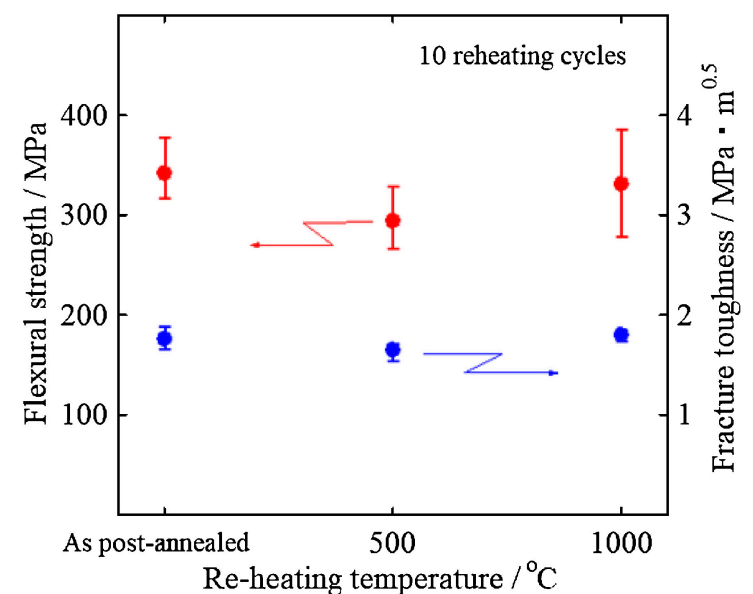

Fig. 7. Flexural strength and fracture toughness of specimen $60 \mathrm{~A}$ (sintered at $1650^{\circ} \mathrm{C}$ for $4 \mathrm{~h}$ ) post-annealed at $1500^{\circ} \mathrm{C}$ for $120 \mathrm{~h}$ after a 10 -cycle heat test.

ceramics in this study can be considered as a composite material of mullite and silica glass or mullite and cristobalite. In Fig. 6, the thermal expansion curve of the postannealed $60 \mathrm{~A}$ specimen includes the effect of the transformation of cristobalite with volume change. Such volume change will lead to residual stresses, depending on heat cycles, affecting the mechanical properties of the resultant mullite ceramics. The thermal expansion of silica glass from room temperature to $1000^{\circ} \mathrm{C}$ is $5.5 \times 10^{-7} / \mathrm{K}$, which is much smaller than that of mullite $\left(5.3 \times 10^{-6} / \mathrm{K}\right)$, whereas the thermal expansion coefficient of cristobalite is $1.9 \times 10^{-5} / \mathrm{K}$ higher than that of mullite. ${ }^{28)}$ Therefore, we studied the effect of the thermal cycles on the mechanical properties up to $1000^{\circ} \mathrm{C}$.

Figure 7 shows the strength and the fracture toughness at room temperature after 10 heat cycles from room temperature to 500 or $1000^{\circ} \mathrm{C}$ for the $60 \mathrm{~A}$ specimen postannealed at $1500^{\circ} \mathrm{C}$ for $120 \mathrm{~h}$. Although residual stress was expected to have a large effect on the mechanical properties, the effects of the thermal history on the flexural strength and fracture toughness of the post-annealed $60 \mathrm{~A}$ specimen were not significant at room temperature in this result. In order to discuss the effect of the residual stresses on the mechanical properties after heat treatment, Fig. 8 shows the linear thermal expansion/shrinkage behavior for the post-annealed $60 \mathrm{~A}$ test piece, together with those of pure mullite and cristobalite on cooling from $1500{ }^{\circ} \mathrm{C}$ to room temperature using the data calculated by Sato et al. ${ }^{22}$ )

The volume change in the post-annealed $60 \mathrm{~A}$ specimen accompanied by the transformation of the grain boundary cristobalite on heating would be a volume shrinkage of about $5.6 \%,{ }^{22)}$ but the residual stress is expected to become zero due to stress relaxation in the remaining glassy phase during higher-temperature annealing. In the cooling process from $1500^{\circ} \mathrm{C}$ to room temperature, the compressive stresses on the cristobalite will arise in cristobalite up to the temperature $\left(\sim 250^{\circ} \mathrm{C}\right)$ at which the phase transformation from a high-temperature phase to a low-temperature phase is observed. The phase transformation of the cristobalite

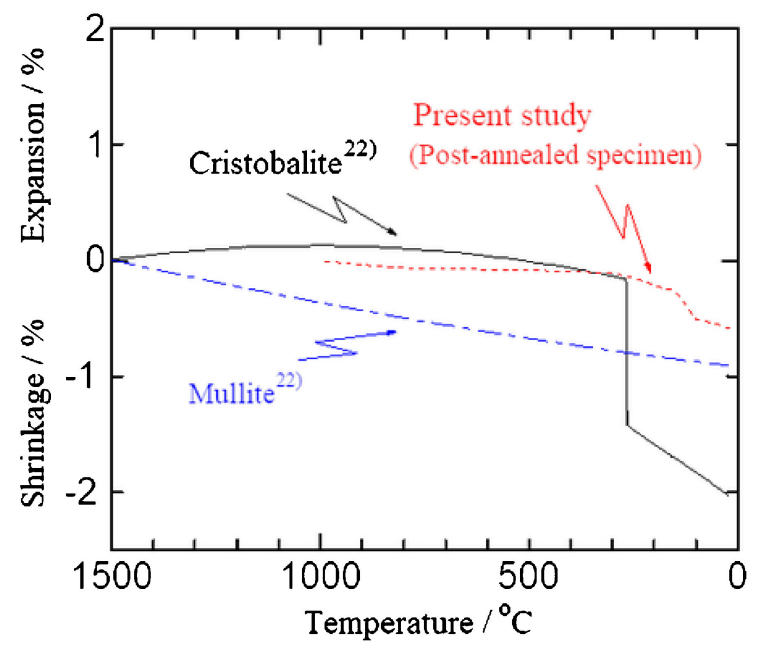

Fig. 8. Change in thermal behavior of pure mullite and cristobalite during cooling from $1500{ }^{\circ} \mathrm{C}$ to room temperature (RT) calculated from their thermal expansion coefficients, compared with that measured for the post-annealed specimen $60 \mathrm{~A}$ from RT to $1000^{\circ} \mathrm{C}$.

causes it to shrink rapidly, relaxing the residual stress on the mullite phase and finally slightly changing the residual stress from tensile to compressive. However, the residual stress present in the specimen did not induce cracks of the size that affect the mechanical properties of the specimen, and the fracture toughness value was not significantly affected. The fracture toughness, at room temperature, of the post-annealed specimen was almost the same as mullite ceramics with $64-74 \mathrm{wt} \%$ alumina content measured by the chevron-notched beam method. ${ }^{32)}$ In other words, the effect of thermal history on the mechanical properties of the specimens subjected to reheating and cooling was insignificant. This result can be explained by the following reasons: Firstly, the size of the cristobalite is as fine as a few tens of nanometers. ${ }^{33)}$ Furthermore, the specimens used in the experiments were small, with a cross-sectional area of $3 \times 4 \mathrm{~mm}^{2}$, so the shape effect of the thermal mismatch is also expected to be small.

In the case of the mullite-silicon carbide composite reported by Nakao et al., the $100-200 \mu \mathrm{m}$ cracks produced by the Vickers indenter were able to heal at above $1000^{\circ} \mathrm{C}$ in air. ${ }^{34)}$ It was found that the healing activator recovered the cracks generated on the surface of the ceramics at a low temperature and in a short time. From these results, the effect of thermal mismatch on mechanical strength and fracture toughness of the mullite-cristobalite ceramics at room temperature can be explained by the crack healing shown by the residual glassy phase. Therefore, it was concluded that the mullite ceramics containing very fine cristobalite prepared in this study can act as excellent structural ceramics even under thermal cycles.

\subsection{Effect of crystallization of the grain boun- dary phase on high-temperature strength}

Plots of three-point flexural strength as a function of temperature for the as-sintered and post-annealed $60 \mathrm{~A}$ 


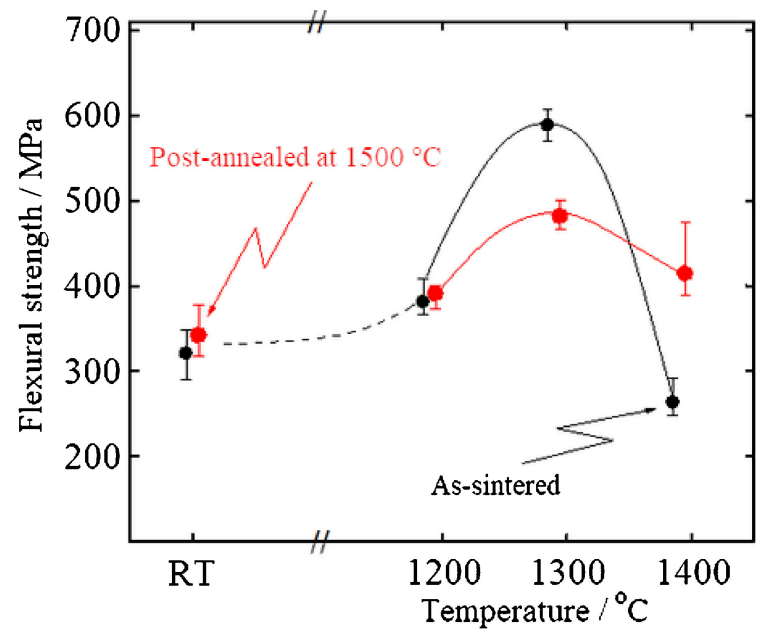

Fig. 9. Variation of the flexural strength of the $60 \mathrm{~A}$ specimens (sintered at $1650^{\circ} \mathrm{C}$ for $4 \mathrm{~h}$ ) post-annealed at $1500^{\circ} \mathrm{C}$ for $120 \mathrm{~h}$ and the as-sintered specimens as a function of temperature.

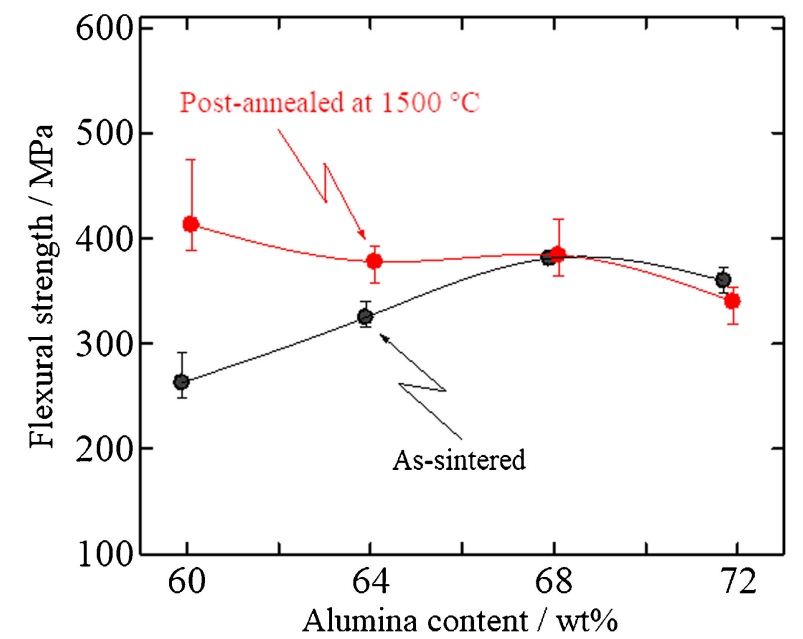

Fig. 10. Flexural strength evaluated at $1400^{\circ} \mathrm{C}$ in the air for the specimens post-annealed at $1500^{\circ} \mathrm{C}$ for $120 \mathrm{~h}$ and the as-sintered specimens (sintered at $1650^{\circ} \mathrm{C}$ for $4 \mathrm{~h}$ ) as a function of alumina content.

specimens at $1500^{\circ} \mathrm{C}$ for $120 \mathrm{~h}$ are shown in Fig. 9. The strength of the as-sintered $60 \mathrm{~A}$ specimen showed a strong temperature dependence, and it reached $600 \mathrm{MPa}$ at $1300^{\circ} \mathrm{C}$, which was approximately twice the strength at room temperature. However, the flexural strength of the as-sintered $60 \mathrm{~A}$ measured at $1400^{\circ} \mathrm{C}$ decreased drastically below the strength at room temperature. Meanwhile, the strength of the post-annealed 60A showed a higher flexural strength at $1300^{\circ} \mathrm{C}$ than that at room temperature, and maintained its high value even at $1400^{\circ} \mathrm{C}$.

These results demonstrate the effect of crystallization of the grain boundary glassy phase on the mechanical properties of the mullite ceramics with silica-rich compositions. Figure 10 shows the relationship between alumina content and flexural strength at $1400^{\circ} \mathrm{C}$. The flexural strength of the as-sintered specimens at $1400^{\circ} \mathrm{C}$ tended to increase with an increasing alumina content, whereas the

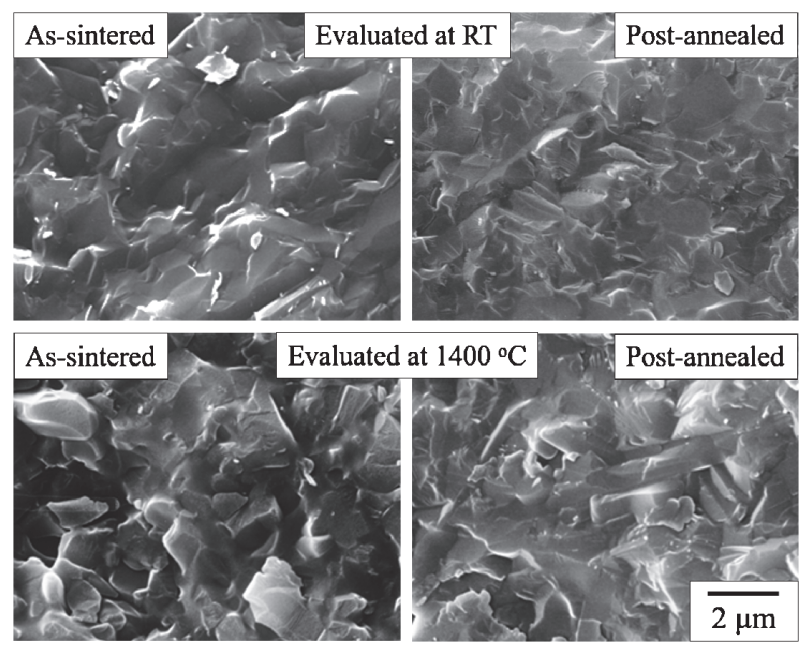

Fig. 11. Scanning electron micrographs of the fracture surface evaluated at room temperature and $1400^{\circ} \mathrm{C}$ of the $60 \mathrm{~A}$ specimens as-sintered at $1650^{\circ} \mathrm{C}$ for $4 \mathrm{~h}$ and post-annealed at $1500^{\circ} \mathrm{C}$ for $120 \mathrm{~h}$.

high-temperature strength of the post-annealed specimens gradually decreased with an increasing alumina content. However, the flexural strength of the post-annealed $60 \mathrm{~A}$ was higher than that of $71.8 \mathrm{~A}$, indicating the usefulness of the grain boundary design by suitable post-annealing in developing better high-temperature structural ceramics.

Figure 11 shows typical fracture surfaces after mechanical tests at room temperature and $1400^{\circ} \mathrm{C}$ for the assintered and post-annealed $60 \mathrm{~A}$ silica-rich mullite ceramics. In the fracture surface at room temperature, a little influence of crystallization of the glassy phase was observed. Specimens with cristobalite at the grain boundaries had smaller irregular fracture surfaces. Moreover, the fracture surface at $1400^{\circ} \mathrm{C}$ was greatly affected by the post-annealing, and the pull-out of the elongated mullite grains was observed in the post-annealed $60 \mathrm{~A}$, which contains a small amount of glassy phase and very fine cristobalite crystals. In contrast, no obvious mullite grain pull-out was observed in the as-sintered 60A.

To investigate the effect of post-annealing on flexural strength, Fig. 12 compares the stress-strain curves measured at $1400^{\circ} \mathrm{C}$ for glass-containing specimens $60 \mathrm{~A}$ and $68 \mathrm{~A}$ before and after post-annealing. For $60 \mathrm{~A}$, the glasscontaining specimen fractured with a large plastic deformation before post-annealing, whereas the post-annealed 60 A showed a typical stress-strain curve of the hightemperature structural ceramics with a higher stress value. The as-sintered and post-annealed 68A specimens showed almost the same strength as shown in Fig. 10, but creep resistance was expected to be lower in the as-sintered specimens because they fractured with plastic deformation whereas brittle fracture was observed in the post-annealed specimens.

Thus, it was demonstrated that the grain boundary design or the crystallization of the grain boundary glassy phase by the post-annealing of the silica-rich mullite ceramics containing glass at the grain boundary had a sig- 


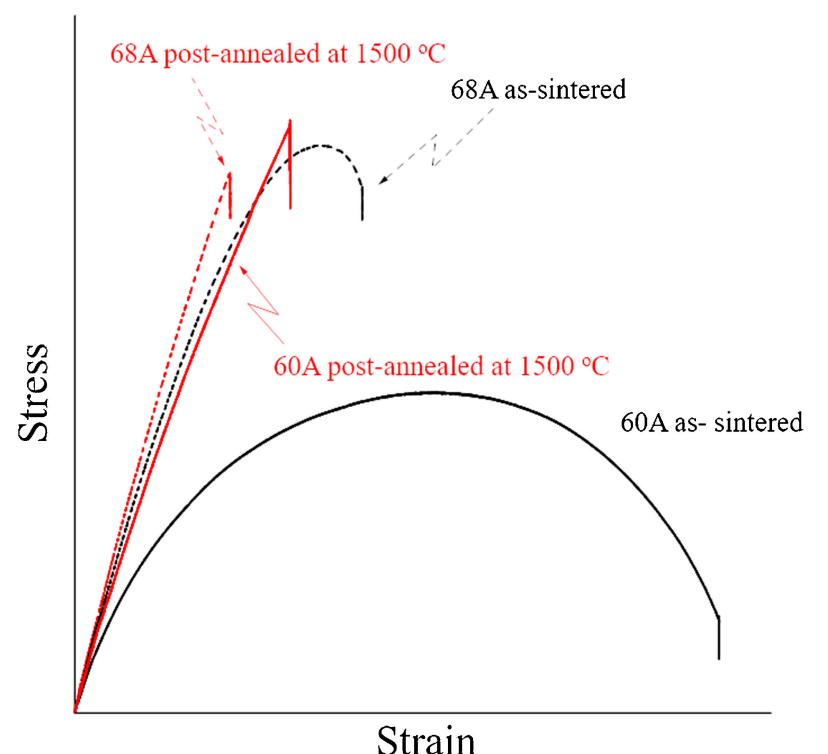

Fig. 12. Typical stress-strain curves for the $60 \mathrm{~A}$ and $68 \mathrm{~A}$ postannealed specimens at $1500^{\circ} \mathrm{C}$ for $120 \mathrm{~h}$ and the as-sintered specimens (sintered at $1650^{\circ} \mathrm{C}$ for $4 \mathrm{~h}$ ) evaluated at $1400^{\circ} \mathrm{C}$ in air.

nificant effect on the high-temperature flexural strength. We have previously reported that the high-temperature strength of the mullite ceramics containing glass dramatically changed depending on the amount of the grain boundary glassy phase. ${ }^{6}$ ) The flexural strength of the mullite ceramics, such as $60 \mathrm{~A}$, containing glass measured at $1400{ }^{\circ} \mathrm{C}$ decreased to below room temperature strength with plastic deformation due to a decrease in the viscosity of the grain boundary glassy phase, as shown in Fig. 12. Crystallizing the grain boundary glassy phase into cristobalite suppressed its plastic deformation in the mullite ceramics at high temperatures and improved its strength.

Also, Fig. 12 suggests that if the grain boundary is appropriately designed using silica-rich composition mullite ceramics, the crystallization of the grain boundary phase can improve static fracture characteristics such as creep. In particular, this study demonstrates that the degree of softening and plastic deformation of the mullite grain boundary phase is affected by the amount of residual glassy phase. Thus, the optimization of the amount of grain boundary glassy phase and/or grain boundary design is essential for improving the strength of mullite ceramics at higher temperatures. The microstructure of the fine precipitated cristobalite located within the mullite grain boundary may affect its high-temperature mechanical properties; however, further investigation (e.g., by creep deformation analysis and microstructure observation) is required to confirm this assumption.

\section{Conclusions}

In this study, we used post-annealing to design the grain boundary in mullite ceramics with silica-rich compositions and/or good sinterability to improve their mechanical properties. The important conclusions of the study are:
(1) Full densification of the mullite ceramics at low temperatures was possible using silica-rich raw powders under optimized conditions.

(2) Most of the glassy phase existing in the mullite grain boundaries after densification crystallized from amorphous to cristobalite by annealing at $1500^{\circ} \mathrm{C}$. The precipitated cristobalite particles were very fine.

(3) The precipitated cristobalite crystals did not significantly influence the mechanical properties at room temperature.

(4) The flexural strength of the silica-rich mullite ceramics at high temperatures was improved by the crystallization of the glassy phase in the grain boundaries. In other words, crystallization of the glassy phase in the grain boundaries suppressed the degradation of flexural strength until $1400^{\circ} \mathrm{C}$.

These results demonstrate that the crystallization of the grain boundaries of the high-temperature structural ceramics by suitable processing is a powerful tool for developing high-performance structural ceramics using a costeffective and eco-friendly sintering process.

Acknowledgments We express our sincere gratitude to Dr. Shuzo Kanzaki of the National Institute of Advanced Industrial Science and Technology for his helpful discussions, and Editage (www.editage.com) for English language editing.

\section{References}

1) K. S. Mazdiyasni and L. M. Brown, J. Am. Ceram. Soc., 55, 548-552 (1972).

2) P. A. Lessing, R. S. Gordon and K. S. Mazdiyasni, J. Am. Ceram. Soc., 58, 149 (1975).

3) P. C. Dokko, J. A. Pask and K. S. Mazdiyasni, J. Am. Ceram. Soc., 60, 150-155 (1977).

4) S. Kanzaki, H. Tabata, T. Kumazawa and S. Ohta, J. Am. Ceram. Soc., 68, C6-C7 (1985).

5) M. G. M. U. Ismail, Z. Nakai and S. Somiya, J. Am. Ceram. Soc., 70, C7-C8 (1987).

6) T. Kumazawa, S. Kanzaki, S. Ohta and H. Tabata, J. Ceram. Soc. Jpn., 96, 85-91 (1988).

7) H. Ohira, M. G. M. U. Ismail, Y. Yamamoto, T. Akiba and S. Somiya, J. Eur. Ceram. Soc., 16, 225-229 (1996).

8) M. Ashizuka, T. Okuno and Y. Kubota, J. Ceram. Soc. Jpn., 97, 662-668 (1989).

9) E. Fernandez and C. Baudin, J. Eur. Ceram. Soc., 21, 2243-2251 (2001).

10) H. Ivankovic, E. Tkalcec, R. Rein and H. Schmidt, J. Eur. Ceram. Soc., 26, 1637-1646 (2006).

11) H. Schneider, J. Schreuer and B. Hildmann, J. Eur. Ceram. Soc., 28, 329-344 (2008).

12) M. Fukushima and Y. Yoshizawa, J. Eur. Ceram. Soc., 36, 2947-2953 (2016).

13) T. Kumazawa, K. Kanzaki, J. Asaumi, O. Abe and H. Tabata, J. Ceram. Soc. Jpn., 94, 485-490 (1986).

14) T. Kumazawa, F. Ozeki and H. Suzuki, J. Soc. Powder Technol., Jpn., 56, 519-525 (2019).

15) S. Saito, S. Somiya and K. Kato, J. Jpn. Soc. Powder Powder Metall., 13, 186-191 (1966).

16) S. C. Singhal and F. F. Lange, J. Am. Ceram. Soc., 58, 
433-435 (1975).

17) A. Tsuge, K. Nishida and M. Komatsu, J. Am. Ceram. Soc., 58, 323-326 (1975).

18) M. Mitomo and K. Mizuno, J. Ceram. Soc. Jpn., 94, 106-111 (1986).

19) Y. Kim, M. Mitomo and T. Nishimura, J. Am. Ceram Soc., 85, 1007-1009 (2002).

20) H. Choi, Y. Kim, M. Mitomo, T. Nishimura, J. Lee and D. Kim, Scripta Mater., 50, 1203-1207 (2004).

21) Y. Kim, S. H. Jang, T. Nishimura, S. Choi and S. Kim, J. Eur. Ceram. Soc., 37, 4449-4455 (2017).

22) T. Sato, Y. Sawabe, Y. Ohya, M. Sugai and Z. Nakagawa, J. Ceram. Soc. Jpn., 108, 345-349 (2000).

23) T. Sato, Y. Sawabe, Y. Ohya, M. Sugai and Z. Nakagawa, J. Ceram. Soc. Jpn., 107, 838-843 (1999).

24) P. Scherrer, Nachrichten von der Gesellschaft der Wissenschaften zu Göttingen, 26, 98-100 (1918).

25) D. Munz, R. T. Bubsey and J. L. Shannon, Jr., J. Am.
Ceram. Soc., 63, 300-305 (1980).

26) R. Raj, Acta Metall. Mater., 38, 1413-1416 (1990).

27) D. R. Clarke, J. Am. Ceram. Soc., 70, 15-22 (1987).

28) D. Taylor, Trans. J. Br. Ceram. Soc., 83, 129-134 (1984).

29) F. F. Lange, "Fracture Mechanics of Ceramics", vol. 2, Ed. by R. C. Bradt et al., Plenum Press, New York. (1974) pp. 599-612.

30) R. R. Tummala and A. L. Friedberg, J. Am. Ceram. Soc., 52, 228-229 (1969).

31) N. Claussen, J. Steeb and R. F. Pabst, Am. Ceram. Soc. Bull., 56, 559-562 (1977).

32) T. Kumazawa, S. Ohta, H. Tabata and S. Kanzaki, J. Ceram. Soc. Jpn., 97, 895-902 (1989).

33) Y. Kobayashi, O. Ohira and H. Isoyama, J. Ceram. Soc. Jpn., 111, 122-125 (2003).

34) W. Nakao, T. Osada, K. Yamane, K. Takahashi and K. Ando, J. Jpn. Inst. Met. Mater., 69, 663-666 (2005). 